\title{
СЕМАНТИЧЕСКИЕ ОСОБЕННОСТИ АНГЛИЙСКИХ ФРАЗЕОЛОГИЗМОВ С КОМПОНЕНТОМ-ГЕОРТОНИМОМ
}

\section{SEMANTIC FEATURES OF ENGLISH PHRASEOLOGICAL UNITS WITH THE COMPONENT-GEORTONYM}

I. Puchkova

Summary: This article deals with English phraseological units with components-names of holidays. The paper identifies the factors that cause the appearance of these phraseological in the language. The phraseological units are classified into thematic groups, their semantics is analyzed. Semantic changes in their structure are pointed out. Special attention is given to the evaluative component or their meaning.

Keywords: the English language, phraseological unit, geortonym, semantics, emotiveness, evaluative component.
Пучкова Ирина Николаевна

К.филол.н., дочент, Московский городской педагогический университет

irenep@yandex.ru

Аннотация: В статье анализируются английские фразеологизмы с компонентами-названиями праздников. Выявляются факторы, обуславливающие появление в языке фразеологизмов подобного рода. Выделяются тематические группы и проводится анализ семантики данных фразеологизмов. Выявляются изменения в семантической структуре геортонимов, особое внимание уделяется оценочному компоненту значения.

Ключевые слова: английский язык, фразеологизм, геортоним, семантика, эмотивность, оценочность.
И зучение фразеологического фонда различных языков традиционно привлекало внимание лингвистов. Особенно активно фразеология изучается в последнее время, поскольку она является инвариантной частью языковой картины мира и в ней отражается национальный менталитет (Балабас, 377). Поскольку названия праздников (геортонимы) находятся на периферии системы имен собственных, им еще не уделено должного внимания в лингвистике. Вместе с тем, фразеологизмы с компонентом-геортонимам еще не получили достаточного освещения. Под геортонимами понимаются названия праздников, юбилеев, торжеств (Суперанская, 197). Объектом данного исследования послужили английские фразеологизмы (устойчивые выражения, пословицы, поговорки) с компонентами - геортонимами (названиями праздников, отмечаемых в англоязычном мире). Данные фразеологизмы были отобраны методом поиска и выборки из специализированных словарей (2, 3,4 ,6, 7). Полученный корпус (60 примеров) был систематизирован в зависимости от выражаемого значения и национально-культурных характеристик, ассоциируемых с тем или иным геортонимом в сознании носителей английского языка.

Как показал анализ материала, в составе английских фразеологизмов чаще всего фигурируют названия религиозных праздников. Наиболее освоенным геортонимом в составе английских фразеологизмом является лексема Christmas, также отмечены фразеологические единицы с компонентами Trinity (Троица), Candlemas (Сретение), а также праздники в честь святых. Из нерелигиозных событий во фразеологическом фонде английского языка отмечены Новый год, (Yule), Парад Лорда-Мэра в Великобритании (Lord Mayor's Show) и День Независимости США (the Fourth of July).

Появление в фразеологическом фонде английского языка единиц с компонентом-геортонимом может быть связано с событиями в мировой истории, ассоциируемых с неким праздничным днем. Так, выражение to carry out St. Bartholomew's Day massacre (сделать кому-либо разнос, отругать) напоминает о массовом истреблении протестантов в Париже накануне праздника святого апостола Варфоломея 24 августа 1572 года в Париже. В протестантской Англии известие об истреблении единоверцев вызвало резкое осуждение, поэтому геортоним St. Bartholomew's Day и возникшее на его основе устойчивое выражение приобретают негативную коннотацию.

Фразеологизмы с компонентом-геортонимом связаны с историческим прошлым Великобритании. В средневековой Англии отмечалось немало религиозных праздников как общехристианских, так и связанных с почитанием местных святых. События в жизни людей связывались не с точным временем, а с регулярной сменой времен года и праздников. Этим объясняется наличие в английском языке пословиц и поговорок с названием церковного праздника, связанных с предсказанием погоды, состоянием природы, народными приметами и обрядами и повериями. Например, пословица $A$ green Christmas (вариант Yule) makes a fat churchyard, восходит к тому времени, когда люди жили в плохо отапливаемых помещениях, и существовало поверие, что влажный и сырой воздух или легкие одежды теплой зимой могли 
привести к простудным заболеваниям, которые могли окончиться смертью. Подобные паремии часто рифмованы и ритмическая организованы: On Saint Thomas the Divine kill all turkeys, geese and swine (в день Апостола Фомы праздновался 21 декабря, было принято забивать скот для рождественского стола). Barnaby bright, Barnaby bright, the longest day and the shortest night (11 июня по старому стилю - день святого Варнавы, самый долгий день в году). If Candlemas day be sunny and bright, winter have another flight, If St Paul be fair and clear, it will betide a happy year.

Религиозные праздники в прошлом определяли начало и окончание учебы в университетах, а также начало и окончание судебных сессий, что обусловило появление устойчивых словосочетаний, где происходит генерализация значения геортонима по модели «название праздника > время года, когда отмечается данный праздник», например: Michaelmas term (1. Осенний триместр в университетах. 2. Юр. Осенняя судебная сессия) и Trinity term (1. Весенний триместр в университетах. 2. Весенняя судебная сессия). Ассоциативная связь праздника с началом или окончанием учебы прослеживается и в выражении Christmas graduate (первокурсник, которого отчисляют после первого семестра), что обусловлено практикой отсева студентов после первого семестра, окончание которого приходится на период перед рождественскими праздниками.

Идея темпоральности выражается в фразеологизме at later Lammas (никогда). Lammas - 1 августа, Петров день, праздник урожая, который отмечался только раз в году, в силу географических и природных условий в Англии второго праздника урожая не могло быть никогда. Мысль о быстротечности и недолговечности праздника воспроизводится в фразеологизмах Christmas comes but once a year - «наслаждайтесь быстротечными радостными моментами», After Christmas comes Lent - «не все коту масленица».

Следует отметить, что геортоним Christmas наиболее часто употребим в исследуемом корпусе фразеологизмов (18 примеров).

Среди фразеологизмов, содержащих в своем составе компонент Christmas, многочисленную группу составляют идиомы, описывающие эмоциональное состояние человека, например, выражения to have all the Christmases at once (быть в хорошем настроении), like it's Christmas morning (как праздник), связаны с идеей душевного подъема, который человек испытывает в один из ключевых христианских праздников. Напротив, to cancel somebody's Christmas (буквально «отменить комулибо Рождество» устроить «веселую» жизнь, лииить человека радости), построенный на метафорическом переносе, отражает негативное эмоциональное состо- яние человека. Обращает на себя внимание тот факт, что рождественские праздники в последнее время все больше коммерциализируются, и это отражается на фразеологическим фонде английского языка, а именно, приводит к появлению идиом, где геортоним Christmas приобретает негативные эмотивно-оценочные коннотации. Например, идиома Christmas face имеет значение «недовольное, кислое выражение лица». Появление данного фразеологизма объясняется тем, что в последние десятилетия рождественские праздники у многих ассоциируются с переполненными магазинами, пробками, большими расходами, что и вызывает негативные эмоции и унылый внешний вид.

Под выражением Christmas family понимаются родственники, с которыми люди не видятся и не общаются вживую, коммуникация происходит лишь посредством рождественских открыток. Таким образом, в данном атрибутивном сочетании геортоним приобретает коннотацию «редкий, незначительный, не представляющий ценности».

Эмоциональную оценку с отрицательным знаком несет в себе и выражение Christmas jumper (буквально «рождественский джемпер» - временный партнер по романтическим отношениям, которого используют в качестве утешения на период холодов).

Обесценивание идеи Рождества приводит также к активному употреблению геортонима Christmas с существительными, имеющими негативные эмоциональнооценочные коннотации: Christmas fatigue (рождественская усталость - упадок сил после долгих и насыщенных праздников), Christmas fiend (злой дух рождества - тот, кто не разделяет всеобщего веселья и намеренно портит праздничное настроение - аллюзивный намек на героя книги Доктора Сьюза «Как Гринч- украл Рождество»), Christmas grief (рождественская печаль - печаль от того, что человек не получил желаемых подарков, Christmas hell - рождественский ад - эмоции, которые испытывают работники сферы услуг перед Рождеством.

Следующую группу составляют идиомы, описывающие характер, личностные качества и умственные способности человека: not the brightest bulb on the Christmas Tree - не самый умный, to fall from a Christmas tree - быть наивным, будто вчера родиться, The devil makes his Christmas pies of lawyers' tongues and clerks' fingers (лицемерие и нечестность юристов и чиновников), патриотизм (Fourth of July speech - ура-патриотическая, эмоциональная речь, born on the fourth of July - показная патриотичность). Как видно из примеров, идиомы с компонентами-геортонимами в этой группе имеют негативно-оценочный характер.

Поскольку праздничные, выходные и будние дни 
связаны с занятостью или бездельем, то фразеологизмы с компонентами-геортонимами могут выражать идею «работа/ отдых». Например, в основе фразеологизма to have more business than English ovens at Christmas (быть по горло в делах) лежит традиция отмечать Рождество обильной трапезой, что предполагало большую загруженность печей перед этим праздником.

Фразеологизмы с компонентами-геортонимами отличаются яркой образностью. С помощью построенного на сравнении фразеологизма like turkeys voting for Christmas (копать самому себе яму, соглашаться на заведомо невыгодное предложение) имплицитно-иронически выражается отрицательная оценка ситуации со стороны говорящего. Известно, что неотъемлемым атрибутом традиционного рождественского обеда в англоязычном мире является запеченная индейка. Подобно тому, как индейка, осознающая, что ее съедят на праздник, не желает его скорейшего наступления, так и человек не хочет приближать событие, которое заведомо плохо для него закончится.
Примерами фразеологизмов, выражающих отношение человека к окружающей действительности могут служить фразеологизмы After the Lord Mayor's show (после парада лорда-мэра) - разочаровывающее, заурядное событие после чего-то выдающегося и Christmas came early (удивительное и благополучное разрешение трудной ситуации).

Итак, геортонимы включаются в состав английских фразеологизмов на основе сравнения, метафоризации, метонимии и за счет генерализации значения. Английские фразеологизмы с компонентами-геортонимами отличаются национально-культурным своеобразием, образностью и эмоциональностью. Они отражают представления носителей английского языка об окружающей действительности, природе, повседневной и общественной жизни на определенном этапе исторического развития, а также раскрывают специфику человеческих отношений и оценку внешних и внутренних сторон человеческой личности.

ЛИТЕРАТУРА

1. Балабас Н.Н. К исследованию фразеологизмов Когнитивные исследования языка. Вып. XXXIII: Когнитивные исследования в гуманитарных науках: Материалы Всероссийской конференции с международным участием. Тамбов: Принт-Сервис, 2018. 883 с. С. 375-379

2. Кунин А.В. Англо-русский фразеологический словарь М.: Рус. Яз, 1984- 994 с

3. Словарь Multitran [Электронный ресурc] URL: https://www.multitran.com/m.exe?l1=1\&l2=2 (дата обращения: 30.04.2020)

4. Словарь Urban dictionary [Электронный ресурс] URL: https://www.urbandictionary.com/ (дата обращения: 30.04.2020)

5. Суперанская А.В. Общая теория имени собственного М, Наука, 1973. 367 с

6. Шитова Л.Ф., Брускина Т.Л. Англо-русский словарь идиом и фразовых глаголов. Санкт-Петербург. Лабиринт, 2012. $256 c$.

7. English Idioms and phrases. Приложение. [Электронный ресурc] URL: https://play.google.com/store/apps/details?id=com.funbox.englishidioms\&hl=ru (дата обращения: 30.04 .2020 )

(с) Пучкова Ирина Николаевна (irenep@yandex.ru). 